\title{
Diabetes Melito do Tipo 1A na Primeira Infância de Gêmeos Dizigóticos: Associação Entre Fatores Genéticos e Ambientais
}

\section{apresentação de caso}

LUCIANNE R.M. TANNUS

DHIÃNAH S. OLIVEIRA

ALESSANDRA S.M. MATHEUS

EDNA F. CUNHA

MARÍLIA B. GOMES

Departamento de Diabetes, Serviço de Endocrinologia e Metabologia, Faculdade de Ciências Médicas do Hospital

Universitário Pedro Ernesto

(HUPE), Universidade do Estado

do Rio de Janeiro (UERJ), RJ.
O Diabetes Mellitus tipo 1A diagnosticado antes do $1^{\circ}$ ano de vida é uma condição rara, podendo haver uma associação entre fatores genéticos e ambientais (infecção) que explique tal precocidade. Foi descrita a presença do genoma do Citomegalovírus (CMV) nos linfócitos, em cerca de 15\% de novos casos de DM1. Relatamos os casos de desenvolvimento do diabetes em gêmeos dizigóticos do sexo masculino, nos primeiros 9 meses de idade com identidade nos alelos HLA (DR3/DR4) e história de infecção pelo CMV em ambos, comprovada por lgG+ e PCR urinária. Apenas o $2^{\circ}$ gemelar apresentava o anticorpo anti-GAD positivo $(9,6 \mathrm{Ul} / \mathrm{mL})$. Apesar de tratar-se de gêmeos dizigóticos, cuja taxa de concordância para diabetes, na literatura, é de $3,8 \%$, assumem risco equivalente a monozigóticos (de $40 \%$ ) por apresentarem HLA de alto risco para o diabetes. Acreditamos que tanto a concordância temporal como o início precoce do diabetes são decorrentes da associação entre infecção por CMV e forte suscetibilidade genética. (Arq Bras Endocrinol Metab 2007;51/1:142-145)

Descritores: Diabetes Mellitus tipo 1A; Citomegalovírus; Gêmeos dizigóticos

\section{ABSTRACT}

Early Infancy Onset of Type 1A Diabetes Mellitus in Dizygotic Twins: Association with Genetic and Environmental Factors.

The onset of type 1A diabetes before the first year of age is a rare condition and is probably due to an interaction between genetic and environmental factors (infection), which, together, may explain such an early event. Studies say that about $15 \%$ of newly diagnosed type 1 diabetic patients had human Cytomegalovirus (CMV) specific viral genome in their lymphocytes. We report two cases of dizygotic twins with type 1 diabetes onset in their first 9 months of age, with genetic homogeneity (for HLA DR3/DR4 alleles), a history of CMV infection (positive IgG and urinary PCR) and positive antibody anti-GAD (9.6 Ul/ml), present only in the second twin. Although they were dizygotic twins, which concordance rate is $3.8 \%$, they assume the equivalent risk as monozygotic $(40 \%)$ as they have similar high risk genotype (HLA) for type 1 diabetes. We believe that both time concordance and also the early onset of diabetes are due to an association between infection and the high genetic liability. (Arq Bras Endocrinol Metab 2007;51/1:142-145)

Keywords: Type 1A diabetes; Cytomegalovirus; Dizygotic twins

$\mathrm{O}$ DIABETES MELLITUS TIPO l (DMl) é a endocrinopatia mais prevalente na infância, com incidência progressivamente maior e com acometimento em idade cada vez mais precoce (2). Nos últimos anos, observaramse avanços importantes nos conhecimentos referentes à sua etiopatogenia. Acredita-se que a doença seja um conjunto de distúrbios genéticos heterogêneos, que se expressa por fenótipos semelhantes, em que a interação 
entre genética e fator ambiental seja o fator desencadeante de um processo auto imune cujos marcadores conhecidos são os auto-anticorpos: anticorpo antiilhota pancreática (ICA), auto-anticorpo antiinsulina (IAA), anticorpo anti-descarboxilase do ácido glutâmico (anti-GAD) e anti-tirosina fosfatase (anti-IA2).

Apesar da importância dos fatores genéticos envolvidos no desenvolvimento do DM, um estudo na Finlândia em 22.650 pares de gêmeos, demonstrou que a taxa de concordância em monozigóticos ( $\mathrm{MZ})$ foi de apenas $40 \%$, e de $3,8 \%$ em dizigóticos (DZ), sendo o maior tempo de discordância de início da doença de 6,9 anos entre os gêmeos MZ e 23,6 anos em DZ (3). É conhecido que o risco para DMl é maior no gêmeo cujo irmão manifestou a doença muito jovem (4). Calcula-se que l a $2 \%$ dos casos de DMl possam ser atribuídos a uma virose conhecida. A idéia de que os vírus possam ter importância na etiopatogenia do DMl baseia-se em dados epidemiológicos que demonstram uma relação entre viroses e o subseqüente aparecimento do DMl.

Sabe-se hoje que, das infecções virais conhecidas, as que mais se relacionam com provável lesão pancreática são a parotidite, as enteroviroses, a rubéola congênita e as citomegaloviroses, que atuam de duas maneiras distintas: pela indução de autoimunidade específica para célula beta e por infecção direta e destruição das células beta pancreáticas (5).

Pak e cols. descreveram, em cerca de $15 \%$ de novos casos de DMl, a presença do genoma do CMV nos linfócitos, sugerindo uma associação entre os eventos (5). Embora este dado não tenha sido confirmado por outros autores, o CMV também poderia induzir hipergamaglobulinemia e reação de anticorpos a múltiplos antígenos (6). Isso foi ratificado por estudo que demonstrou relação entre altos títulos de IgG anti CMV e ICA em pacientes com DMl (1). Hoebert e cols. (6) verificaram que certos antígenos de microorganismos mimetizam auto-antígenos (principalmente GAD 65), sendo responsáveis pela ativação de células T auto-reativas. Dessa forma, o CMV pode estar envolvido na perda de tolerância das células $\mathrm{T}$ a auto-antígenos pelo mecanismo de mimetismo molecular, resultando em autoimunidade (6). A infecção viral pode ocorrer antes do nascimento ou em idade muito precoce, e pode ser transmitida via transplacentária, perinatal ou pós-natal, através de contato íntimo ou leite materno. A imaturidade do sistema imune de crianças também favorece persistência de infecção viral, que pode resultar na síntese e produção de interferon $\alpha$, que, por sua vez, induziria a hiperexpressão do complexo de histocompatibilidade classe I nas células endócrinas adjacentes (7).
Estudos epidemiológicos mais recentes sobre a história natural do diabetes ratificam a idéia de que os fatores ambientais como superalimentação da criança, puberdade, baixa atividade física, inflamação, stress psicológico e clima frio, poderiam estar relacionados a um aumento na incidência do diabetes na infância, e principalmente agiriam acelerando ou precipitando a progressão para o DMl após o início do processo auto-imune em faixas etárias precoces (8).

\section{RELATO DE CASO}

Gêmeos dizigóticos do sexo masculino, nascidos de parto cesário (polidrâmnio), prematuro (35 semanas), gesta III para III aborto zero (duas gestações anteriores sem intercorrências). Pré-natal com mais de 6 consultas. Biótipo da mãe: normolínea. APGAR do $1^{\circ}: 8 / 9$ e do $2^{\circ}: 7 / 8$. Este permaneceu 30 dias na UTI neonatal devido a quadro de sepse, apresentando boa evolução após alta hospitalar. Mãe refere varicela em ambos os gêmeos aos 4 meses. História vacinal em dia. Aleitamento materno exclusivo até os 5 meses. Primeiro gemelar permaneceu saudável até os 9 meses, quando necessitou de internação por cetoacidose diabética $(\mathrm{CAD})$. $\mathrm{O}$ segundo gemelar obteve diagnóstico de DMl mais precocemente, aos 8 meses de idade, quando evoluiu para CAD. O primeiro gemelar teve diagnóstico mais tardio, necessitou de doses menores de insulina por $\mathrm{kg}$ de peso, além de apresentar melhor controle metabólico do que o $2^{\circ}$ gemelar. Atualmente, com 2 anos e 7 meses, apresentam-se com 14,4 (percentil 50-75) e 13,6 kg (p25), 90,5 cm (p25) e 90 $\mathrm{cm}$ (p10-25), e suas necessidades de insulina são de 0,7 e $0,8 \mathrm{UI} / \mathrm{kg} / \mathrm{d}$, respectivamente para o $1^{\circ}$ e $2^{\circ}$ gemelares Ambos têm apresentado adequado desenvolvimento

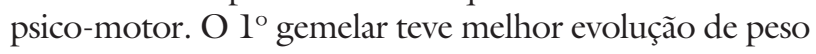
e altura em comparação ao segundo, que apresentou um declínio na curva de peso (tabelas 1, 2, 3 e 4).

\section{DISCUSSÃo}

A associação entre o sistema HLA e diabetes foi descrita pela primeira vez em 1973, quando se demonstrou uma freqüência aumentada do antígeno HLA-B15 em um grupo de pacientes com diabetes tipo 1. Investigações posteriores confirmaram esse relato, registrando também uma associação positiva com os antígenos B8, B18 e B40 e negativa com o antígeno B7 em populações caucásicas (2). Um estudo de 20 famílias brasileiras avaliou relação de genes do sistema HLA com DMl, sendo observada predominância dos ha- 
Tabela 1. Características clínicas e demográficas dos pacientes.

\begin{tabular}{lcc} 
& $\mathbf{1}^{\circ}$ Gemelar & $\mathbf{2}^{\circ}$ Gemelar \\
Peso ao nascimento & $2.250 \mathrm{~g}$ & $2.285 \mathrm{~g}$ \\
Fenótipo & Olhos azuis & Olhos castanhos \\
Idade em que andou & 1 ano & 1 ano (com apoio) \\
Eclosão do quadro & 9 meses & 8 meses \\
Necessidade inicial de insulina Ul/kg/dia & 0,3 & 0,7 \\
\hline
\end{tabular}

Tabela 2. Dados laboratoriais no diagnóstico CAD.

\begin{tabular}{lcc}
\hline & $\mathbf{1}^{\text {o Gemelar }}$ & $\mathbf{2}^{\text {o }}$ Gemelar \\
Glicemia (mg/dl) & 351 & \\
$\mathrm{pH}-$ Gasometria arterial & 7,13 & 7,02 \\
$\mathrm{HCO}$ (mmol/L) & 3,6 & 3 \\
$\mathrm{BE}$ & $-2,6$ & -28 \\
$\mathrm{Na}+(\mathrm{mEq} / \mathrm{L})$ & 139 & \\
$\mathrm{~K}+(\mathrm{mEq} / \mathrm{L})$ & 4,9 & \\
\hline
\end{tabular}

Tabela 3. Sorologia.

\begin{tabular}{|c|c|c|c|c|}
\hline & $1^{\circ}$ Gemelar & $2^{\circ}$ Gemelar & Mãe & Pai \\
\hline Sífilis-VDRL & Não reagente & Não reagente & & \\
\hline Rubéola IgM & Não reagente & Não reagente & & \\
\hline Rubéloa lgG & Indeterminado & $\begin{array}{l}\text { Reagente } \\
\text { (40 Ul/ml) }\end{array}$ & & \\
\hline Toxoplasmose IgM & Não reagente & Não reagente & & \\
\hline Toxoplasmose IgG & Não reagente & Não reagente & & \\
\hline Citomegalovírus IgM & Não reagente & Não reagente & Não reagente & \\
\hline $\lg G$ & $\begin{array}{l}\text { Reagente } \\
\text { (57 Ul/ml) }\end{array}$ & $\begin{array}{l}\text { Reagente } \\
\text { (64 Ul/ml) }\end{array}$ & $\begin{array}{c}\text { Reagente } \\
(2,15 \mathrm{Ul} / \mathrm{ml})\end{array}$ & \\
\hline PCR urina CMV & Positivo & Positivo & & \\
\hline Anti-GAD diagnóstico & Negativo & Positivo & & \\
\hline (normal < $1 \mathrm{Ul} / \mathrm{ml}$ ) & $(0,2 \mathrm{Ul} / \mathrm{ml})$ & $(9,6 \mathrm{Ul} / \mathrm{ml})$ & & \\
\hline Anti-GAD atual (UI/ml) & 0,8 & 1,7 & 0,1 & $<0,1$ \\
\hline Anti-IA2 (normal $<1 \mathrm{UI} / \mathrm{ml})$ & 0,9 & 0,6 & 0,5 & $<0,1$ \\
\hline
\end{tabular}

Tabela 4. Alelos do sistema HLA.

\begin{tabular}{lcc}
\hline & $\mathbf{1}^{\circ}$ Gemelar & $\mathbf{2}^{\circ}$ Gemelar \\
Classe I - Locus A & A02/A31 & A02/A31 \\
Locus B & B39/B50 & B39/B50 \\
Locus C & Cw05/Cw07 & Cw05/Cw07 \\
Classe II - Locus DRB1 & DRB1*04/DRB1*13 & DRB1*04/DRB1*13 \\
Locus DRB3/B4/B5 & DRB3/DRB4 & DRB3/DRB4 \\
Locus DQB1 & DQB1*03/DQB1*03 & DOB1*03/DOB1*03 \\
\hline
\end{tabular}


plótipos A2B8, A2B15 e A9B15 na população diabéti$\mathrm{ca}$, incluindo gêmeos. $\mathrm{O}$ aumento na freqüência de haplótipos A2B8 e A2B15 também foi verificado em familiares de diabéticos, concomitante à demonstração da redução de freqüência de haplótipos A2B5 e $\mathrm{A} 2 \mathrm{~B} 12$, sugerindo papel protetor destes últimos no desenvolvimento de diabetes (2).

Um estudo finlandês mostrou que haplótipos A2, Cwl, B56, DR4, DQ8 são o terceiro haplótipo mais comum em DMl e têm o maior risco absoluto haplótipoespecífico para desenvolvimento de DMl. Alelos HLA-A diferentes de $\mathrm{A} 2$ não são comuns na população em geral, e não estão associados com DMl. A24, A3 e A2 no haplótipo Cw3, B62, DR4, DQ8; e A28, A2 e Al no Cw7, B8, DR3, DQ2 também apresentaram associação com DMl. Esses haplótipos foram encontrados em 33\% dos DMl e apenas em 10,3\% de pacientes não diabéticos, sendo esta associação estatisticamente significativa (9).

Sabe-se que mais de $90 \%$ dos pacientes com DMl apresentam os antígenos DR3 e/ou DR4 em comparação aos $58 \%$ observados na população geral (2). Ressalta-se maior freqüência, de 35 a $58 \%$, dos heterozigotos DR3/DR4 nos diabéticos em comparação à descrita nos controles, de 2,4 a $6 \%$ (2), como também o maior risco relativo conferido por esses antígenos em portadores de DMl no Rio de Janeiro.

Estudos em familiares de DMl mostraram aumento significativo de números de irmãos diabéticos nos portadores de dois haplótipos idênticos e conseqüente diminuição naqueles com haplótipos diferentes. Considera-se que, até os 25 anos de idade, a probabilidade de irmãos sadios com haplótipos idênticos ao do diabético desenvolverem a doença é de 10 a 20\%; em irmãos semiidênticos, $5 \%$, e não idênticos, em torno de $1 \%$.

Estudos mais específicos do locus DR e locus A, $\mathrm{B}$ e C de diabéticos, sugerem que os mesmos estariam em desequilíbrio de associação com o locus $\mathrm{DQ}$, onde residiria a relação primordial com a moléstia.

Atualmente, considera-se que o sistema HLA seja responsável por $60 \%$ da predisposição genética ao $\mathrm{DMl}$, sendo então sugerida a participação de outros sistemas genéticos na suscetibilidade à doença.

$\mathrm{O}$ aumento da incidência de DMI em crianças, crescente nos últimos anos, é consistente com maior participação ambiental no desenvolvimento dessa patologia (10). As diferentes incidências mundiais de DMl podem ser parcialmente justificadas por participação do meio ambiente, em algum momento da história natural do DMl, através das agressões às células beta por agentes infecciosos, agentes quimiotóxicos e possivelmente alterações no aspecto nutricional em organismos geneticamente predispostos.
No caso relatado, entretanto, observamos o aparecimento mais precoce do que o habitual do diagnóstico da doença, além de concordância temporal na sua apresentação.

É interessante notar que ambos apresentam o alelo $\mathrm{DRBI}^{*} 13$ que está associado à proteção para $\mathrm{DMl}$, e os alelos $\mathrm{DQB1}{ }^{*} 03$ e $\mathrm{DRB} 1{ }^{*} 04$ relacionados à suscetibilidade para a doença.

Além disso, apesar de tratar-se de gêmeos dizigóticos cuja taxa de concordância é de 3,8\% (3), o risco para o desenvolvimento de doença é equivalente ao de gêmeos monozigóticos, isto é, de $40 \%$, por apresentarem alelos do sistema HLA idêntico de alto risco $\left(\mathrm{DRB}^{*} 04 / \mathrm{DRBI}{ }^{*} 13 / \mathrm{DRBI}{ }^{*} 03 / \mathrm{DQB}{ }^{*} 03\right)$

Concluímos que a concordância temporal e $\mathrm{o}$ aparecimento precoce da doença nestes casos sugerem sua associação com a infecção por CMV, comprovada por sorologia e PCR urinário.

\section{REFERÊNCIAS}

1. Nicoletti F, Scalia G, Lunetta M, Condorelli F, Di Mauro M, Barcellini W, et al. Correlation between islet cell antibodies and anti-cytomegalovirus $\lg \mathrm{M}$ e $\lg \mathrm{G}$ antibodies in healthy first-degree relatives of type 1 (insulin dependent) diabetes patients. Clin Immunol Immunopathol 1990;55:139-47.

2. Gomes MB, Sarno EN, Chacra AR. Etiopatogenia do diabetes mellitus tipo 1. Aspectos genéticos e fatores ambientais. Arq Bras Endocrinol Metab 1989;33:28-31.

3. Hyttinen V, Kaprio J, Kinnunen L, Koskenvuo M, Tuomilehto $\mathrm{J}$. Genetic liability of type diabetes and the onset age among 22650 young Finnish twin pairs. Diabetes 2003;52:1052-10.

4. Price P, Olver SD. Animal models of human immunopathological disease - syndromes induced by cytomegalovirus infection. Clin Immunol Immunopathol 1996;80:215-24.

5. Pak CY, Eun HM, Mcarthur RG, Yoon JW. Association of cytomegalovirus infection with autoimmune type 1 diabetes. Lancet 1988;2(8601):1-4.

6. Hiemstra HS, Schloot NC, Veelen PAV, Willemen SJM, Franken KLMC, Rood JJV, et al. Cytomegalovirus in autoimmunity: T cell crossreactivity to viral antigen and autoantigen glutamic acid decarboxylase. PNAS 2001;98:398-1.

7. Flodström M, Tsai D, Fine C, Maday A, Sarvetnick N. Diabetogenic potencial of human pathogens uncovered in experimentally permissive $\beta$-cells. Diabetes 2003;52:2025-34.

8. Dalquist G. Can we slow the rising incidence of childhoodonset autoimmune diabetes? The overload hypothesis. Diabetologia 2006;49:20-4.

9. Fennessy $M$, Metcalfe $K$, Hitman GA, Niven M, Biro PA, Tuomilehto J, et al. A gene in the HLA class I region contributes to susceptibility to IDDM in the Finnish population. Childhood Diabetes Finland (dime) Study Group. Diabetologia 1994;37:937-44.

10. Gillespie KM, Bain SC, Barnett AH, Bingley PJ, Christie MR, Gill GV, et al. The rising incidence of childhood type 1 diabetes and reduced contribution of high-risk HLA haplotypes. Lancet 2004;364:1699-700.

Endereço para correspondência:

Alessandra Saldanha de Mattos Matheus

Rua João Pessoa 197/1201

24220-330 Niterói, RJ 